Jurnal Matematika Ilmiah STKIP Muhammadiyah Kuningan

Vol. 5 No.2 November 2019

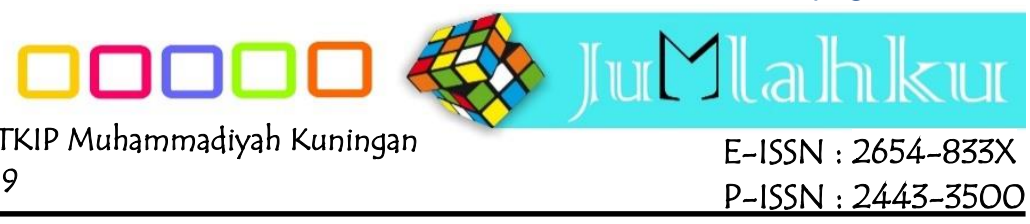

\title{
Penggunaan Multimedia Pembelajaran untuk Membantu Siswa Tuna Rungu dalam Memahami Operasi Bilangan Bulat
}

Erik Santoso a), Roni Rodiyana ${ }^{\text {b) }}$

a) Pendidikan Matematika, FKIP, Universitas Majalengka

eriksantoso@unma.ac.id

b) Pendidikan Guru Sekolah Dasar, FKIP, Universitas Majalengka

ronirodiyana@unma.ac.id

\begin{tabular}{l}
\hline \multicolumn{1}{c}{ Article Info } \\
\hline Keywords : learning \\
multimedia; deaf studen \\
integer operation \\
Submited: $2019-10-10$ \\
Published: $12 / 4 / 2019$
\end{tabular}

The main problem in learning mathematics specifically in children with hearing impairment (hearing impaired) is a learning medium that can help students understand math material well. Learning multimedia can be used so that the material can be delivered and designed properly. Through multimedia can also help students repeat material that is still not mastered. The purpose of this study is to describe the use of multimedia to help students with hearing impairment in SLB N Majalengka to support integer operations. The research method uses qualitative methods with descriptive discussion. The sample in this study were deaf students who were in $S L B N$ Majalengka who replaced two people. The results of this study provide an overview of deaf students in SLB N Majalengka giving a positive view of the use of multimedia and and if seen in two tests deaf students utilize the results on integer operations material.

120

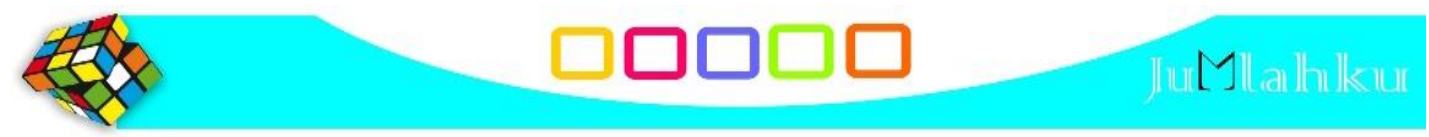


Kata Kunci: multimedia pembelajaran; siswa tuna rungu; operasi bilangan bulat

\begin{abstract}
Abstrak
Masalah utama dalam pembelajaran matematika khususnya pada anak dengan keterbatasan pendengaran (tuna rungu) adalah media pembelajaran yang dapat membantu siswa dalam memahami materi matematika dengan baik. Multimedia pembelajaran dapat digunakan agar materi dapat disampaikan dan dirancang dengan baik. Melalui multimedia juga bisa membantu siswa dalam mengulang materi yang dianggap masih belum dikuasai. Tujuan dari penelitian ini adalah untuk mendeskripsikan penggunaan multimedia dalam membantu siswa tuna rungu SLB $\mathrm{N}$ Majalengka untuk memahami operasi bilangan bulat. Metode penelitian menggunakan metode kualitatif dengan pendekatan deskriptif. Sampel dalam penelitian ini adalah siswa tuna rungu yang berada di SLB N Majalengka yang berjumlah dua orang. Hasil penelitian ini memberikan gambaran bahwa siswa tuna rungu di SLB Negeri Majalengka memliki pandangan positif terhadap penggunaan multimedia dan dan jika dilihat dalam dua kali tes siswa tuna rungu mengalami peningkatan hasilnya pada materi operasi bilangan bulat.
\end{abstract}




\section{PENDAHULUAN}

Matematika merupakan rumpun ilmu murni yang erat kaitannya dengan bilangan. Selain itu matematika erat kaitannya dengan struktur dan ruang. Hal ini sesuai dengan pendapat Mathematics is the abstract study of topics such as quantity (numbers) ( Cook, 2011), structure, space ( Cook, 2011) and change (Csicsery, 2008) (Devlin, 2012). Melalui pengertian tersebut tersirat bahwa konten dasar dari matematika adalah bilangan. Bilangan lebih banyak di berikan di sekolah pada tingkat dasar.

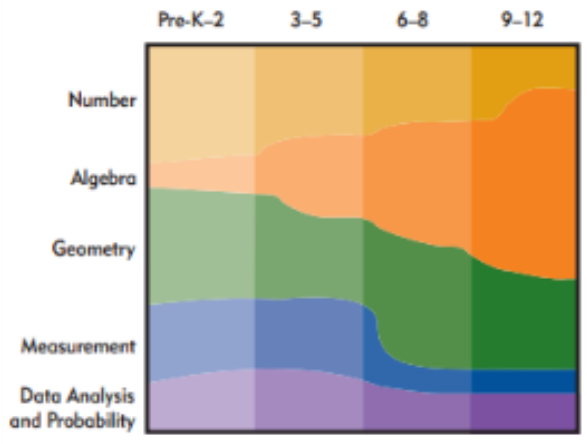

Gambar 1. The Content Standards should receive different emphases across the grade bands ((NCTM), 2001)

Berdasarkan gambar tersebut terlihat bahwa bilangan mendapatkan porsi terbesar di kelas rendah atau bawah pada sekolah dasar. Hal ini didasarkan bahwa bilangan sebagai pondasi pada materi berikutnya. Kita bisa membayangkan jika bilangan yang menjadi pondasi dasar tidak dapat dikuasai oleh siswa, maka siswa akan mengalami kesulitan dalam memahami materi matematika selanjutnya.

Bilangan yang menjadi dasar di awali dengan mengoperasikan bilangan. Salah satu konten matematika di tingkat dasar dan menengah yang sangat menjadi penting untuk tingkatan selanjutnya adalah operasi bilangan bulat. Bilangan bulat pada dasarnya terdiri dari positive integers, negative integers and 0 is neither positive nor negative (Brown, 2011).

Bilangan bulat positif adalah bilangan bulat yang terdiri dari arah sebelah kanan dari 0 , sedangkan bilangan bulat negatif adalah bilangan bulat yang terdiri dari arah sebelah kiri 0 , sedangkan 0 adalah bilangan bulat yang berada di antara bilangan bulat positif dan negatif, sehingga 0 berdiri sendiri. Permasalahan bilangan bulat sering terjadi terutama pada operasi bilangan yang melibatkan dua tanda. Misalkan operasi bilangan bulat negatif dikurangkan dengan operasi bilangan bulat positif.

Operasi bilangan bulat menjadi dasar dikarenakan operasi bilangan

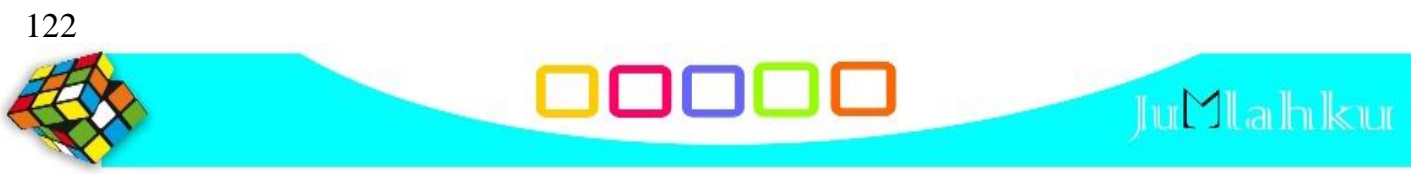


bulat menjadi kemampuan yang selalu di pakai dalam menjawab soal matematika. Materi-materi matematika pada pembelajaran berikutnya selalu melibatkan operasi bilangan bulat. Oleh karena itu, penting untuk dikuasai oleh siswa mengenai operasi bilangan bulat ini.

Perlu upaya guru untuk mampu melakukan inovasi dalam pembelajaran agar materi operasi bilangan bulat ini dapat tersampaikan dengan baik. Terutama guru di Sekolah Luar Biasa (SLB) yang dituntut untuk bisa memberikan materi pembelajaran ini dengan baik. Salah satu tantangan bagi guru SLB adalah menyampaikan materi ini pada siswa tuna rungu. Salah satu alasan perlunya upaya kerja keras adalah bahwa siswa tuna rungu mengalami kesulitan dalam menangkap isi pembicaraan sehingga perlu bimbingan intensif (Salim, 2015). Selain itu seorang guru pada siswa tuna rungu perlu konsisten dalam menyampaikan pembelajarannya (Malatista, B.R. \& Sediyono, E, 2011)

Konsisten dalam pembelajaran dapat di fasilitasi dengan menggunakan media pembelajaran yang cocok untuk anak tuna rungu. Pendengaran yang terbatas perlu dipilih media yang dapat memberikan motivasi kepada siswa. Upaya yang dapat dilakukan oleh guru diantaranya adalah menggunakan multimedia pembelajaran. Multimedia dapat didefinisikan kombinasi dari audio, video, grafik, teks, animasi, dan sebagainya yang diintegrasikan sehingga informasi yang disampaikan dapat tersampaikan dengan baik (Reddi, U.V, 2003).

Pengertian tersebut memberikan gambaran bahwa multimedia penting untuk digunakan karena terdapat kombinasi dari berbagai media yang ada. Multimedia bisa memudahkan siswa dalam memahami materi operasi bilangan bulat, dikarenakan materi yang disajikan sudah di setting terlebih dahulu untuk memudahkan siswa dalam memahami materi tersebut. Multimedia yang dibuat merupakan multimedian interaktif yang di dalamnya terdapat interaksi antara siswa dengan perangkat yang telah dibuat.

Multimedia interaktif dibuat dengan desain khusus sehingga pengguna tinggal menekan tombol sehingga program melakukan perintah tertentu (Fajrianto \& Irawan, 2012). Interaktif dimaknai sebagai sesuatu yang dirancang dengan sistematis oleh peneliti sehingga pembelajaran bisa lebih memotivasi siswa dan siswa dengan mudah dapat belajar dengan baik. Multimedia interaktif juga diartikan agar siswa mampu belajar di mana saja 
dan kapan saja. Salah satu manfaat dari penggunaan multimedia pembelajaran interaktif menambah motivasi siswa dalam proses pembelajaran di kelas (Munir, 2013). Multimedia interaktif yang dibuat perlu memperhatikan tampilan layar dengan mengkombinasikan warna, gambar yang serasi dilihat dari sudut pandang design (Chee, T.S \& Wong, A.F.L, 2003). Berdasarkan uraian latar belakang masalah tersebut maka penelitian ini diarahkan untuk membantu siswa tuna rungu dalam membantu memahami operasi bilangan bulat.

\section{METODE}

Penelitian ini dilaksanakan di SLB Negeri Majalengka dan dilaksanakan pada materi operasi bilangan bulat. Metode penelitian yang digunakan adalah metode penelitian kualitatif deskriptif. Metode kualitatif berusaha memahami dan menafsirkan makna suatu peristiwa dalam waktu tertentu dan dipersepsepsikan oleh peneliti itu sendiri (Gunawan, 2013). Pendekatan yang di guinakan adalah pendekatan deskriptif. Pendekatan deskriptif dimaksudkan untuk eksplorasi mengenai suatu fenomena atau keadaan tertentu (Mulyadi, 2011).
Sampel dalam penelitian ini adalah siswa dengan kondisi kekurangan pendengaran (tuna rungu) sebanyak 2 orang di SLB Negeri Majalengka. Instrumen yang digunakan adalah tes untuk mengukur pemahaman siswa tuna rungu di SLB N Majelangka pada materi operasi bilangan bulat, pedoman wawancara digunakan untuk melihat respon yang ditunjukan dalam penggunaan multimedia dan dokumentasi digunakan sebagai data tambahan untuk memperkuat hasil tes dan wawancara. Analisis data di awali dengan pengumpulan data hasil tes dan wawancara dan diperkuat dengan dokumentasi. Data yang di dapat direduksi antara hasil tes dan wawancara yang dideskripsikan secara lengkap dan terperinci, kemudian langkah selanjutnya yaitu menarik kesimpulan dari hasil mereduksi dan menyajikan data.

\section{HASIL DAN PEMBAHASAN}

Hasil dan pembahasan ditujukan kepada hasil penelitian di lapangan. Hal yang dilakukan di awal adalah dengan melakukan validasi kepada ahli yaitu ahli konten matematika yaitu M. Gilar Jatisunda M.Pd. sebagai ahli konten matematika, kemudian dilanjutkan kepada ahli media oleh Dendi S.Kom. serta ahli kebahasaan untuk anak tuna 
rungu yaitu Bapak Rahmat M.Pd..Hasil analisis dan validasi dari ketiga ahli tersebut di rumuskan dan dibuat dalam suatu perbaikan media yang dibuat. Tampilan awal yang dibuat adalah sebagai berikut:

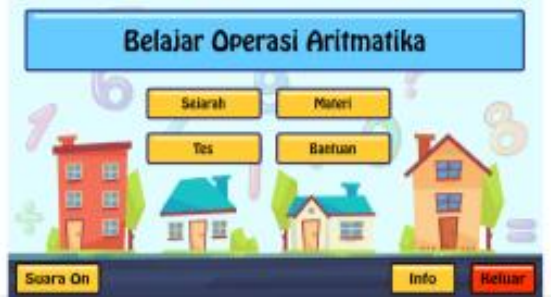

Gambar 1 Tampilan Awal Mutimedia

Tampilan awal adalah tampilan hasil dari ahli media bahwa warna yang ditampilkan sudah diperbaiki. Konten warna menjadi hal yang penting karena memperlihatkan kesesuaian warna satu dengan yang lainnya. Ada empat menu yaitu sejarah berisi tentang sejarah operasi bilangan bulat, kemudian materi berisi materi dan latihan yang dapat dikerjakan oleh siswa, tes berisi soal yang akan ditampilkan untuk di berikan kepada siswa tuna rungu. Menu bantuan seperti halnya menu navigasi untuk membantu orang memahami setiap tombol dalam aplikasi yang dibuat. Suara juga disetting untuk bisa ditampilkan suaranya atau tidak, sedangkan tombol info berisi mengenai pengembangan dari multimedia interaktif.

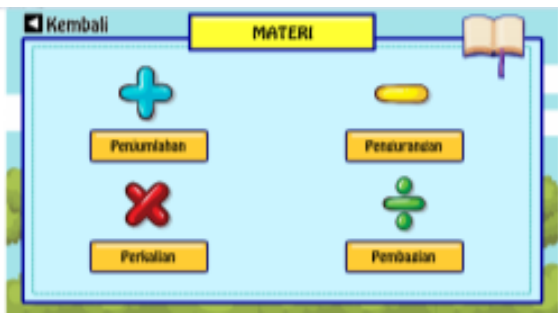

Gambar 2 Tampilan Isi Materi

Tampilan isi materi adalah hasil dari validasi ahli matematika dan ahli konten tuna rungu. Dibuat sederhana dengan maksud agar siswa mampu melihat dengan baik setiap isi materi tersebut. Materi yang disajikan terdiri dari penjulmahan, pengurangan, perkalian dan pembagian. Tombol diperbesar hasil dari validasi ahli konten tuna rungu.

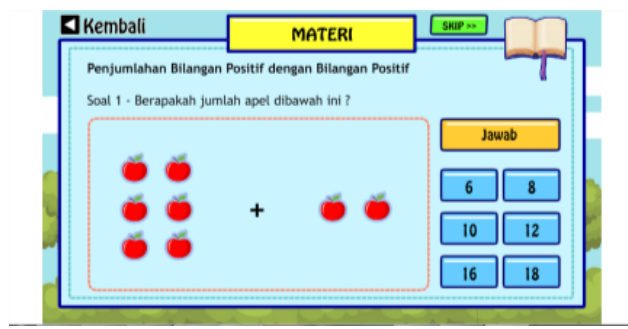

Gambar 3 Tampilan Salah Satu Isi Materi

Hasil validasi konten ahli tuna rungu agar pada awal pembelajaran di perlihatkan benda yang sifatnya nyata 
dan diberikan dulu alternatif jawaban supaya memudahkan siswa untuk memilih jawaban yang akan dipilih. Konten yang disajikan buah apel dimaksudkan agar sering dijumpai oleh siswa.

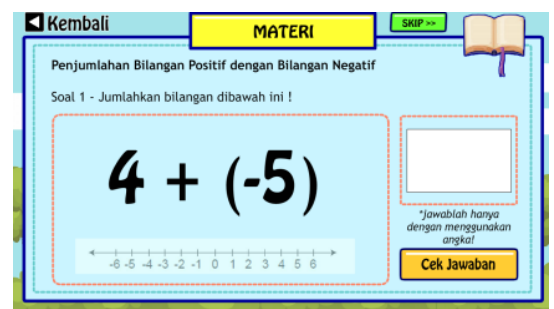

Gambar 4 Tampilan Materi Selanjutnya

Tampilan materi berikutnya di kosongkan supaya siswa mengisi jawaban secara langsung, sehingga siswa dengan mudah untuk menjawabnya. Tombol cek jawab untuk memudahkan siswa mengkonfirmasi jawaban yang diberikan. Respon jika jawaban kurang tepat adalah sebagai berikut:

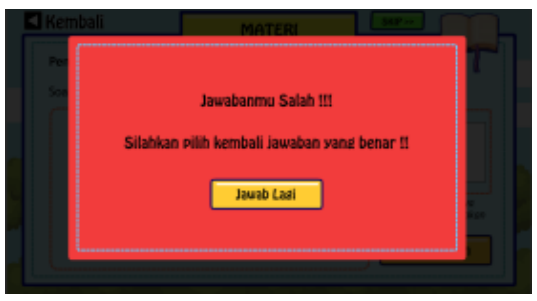

Gambar 5 Tampilan Jawaban Siswa Salah

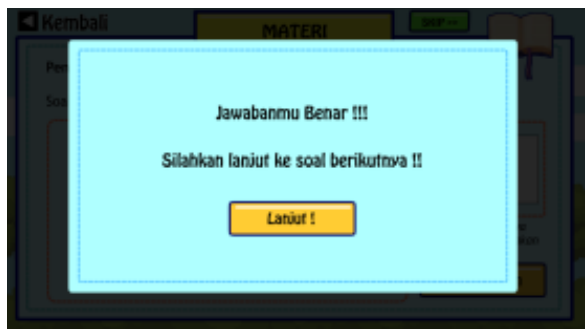

Gambar 6 Tampilan Jawaban Siswa Salah

Tampilan ini didasarkan hasil validasi agar siswa mampu menjawab ullang pertanyaan tersebut. Pada saat ini siswa bisa dibantu oleh guru untuk mengarahkan jawwaban siswa. Hal ini supaya siswa dapat memahami materi dengan baik. Melalui kroscek juga ada motivasi siswa supaya dapat menjawab dengan baik. Berbeda dengan menu tes setiap jawaban benar atau salah akan lanjut pada pertanyaan berikutnya. Setelah semua selesai divalidasi baru dilanjutkan pada proses penelitian. Di awal peneliti melakukan wawancara dan dibantu oleh Ibu Evi S.Pd. sebagai guru kelasnya.

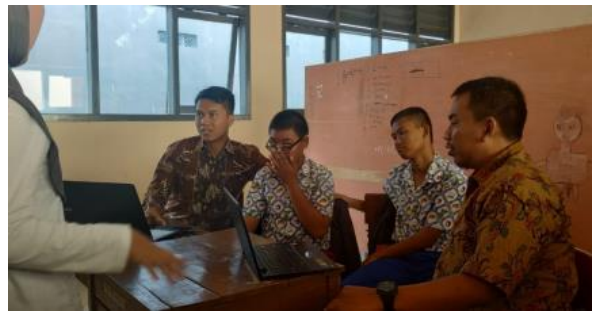

Gambar 6 Proses Wawancara
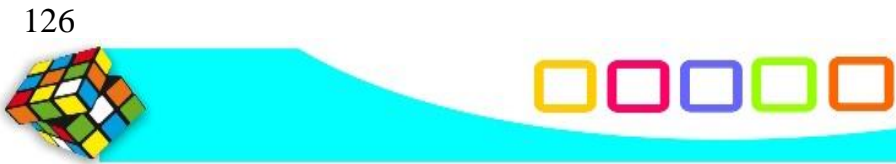
Dapat di rangkum hasil wawancara sebagai berikut ( $\mathrm{X}=$ siswa, $\mathrm{Y}=$ Peneliti):

$Y$ : apakah senang pada mata pelajaran matematika?

$X$ : senang

$Y:$ senang apanya?

$X$ : senang menghitungnya

$Y$ : apa kesulitan belajar matematika?

$X:$ hmmmmm .......?

Y: Senang gak kalau belajar pakai laptop?

$X$ : senang

$Y:$ senang bagaimana?

$X$ :senang karena bisa sambil main

Melalui proses wawancara didapat gambaran sederhana bahwa siswa senang terhadap matematika. Siswa juga senang terhadap bu Evi yang mengajar matematikanya. Proses wawancara juga dilanjutkan bersama bu Evi, peneliti bertanya materi di operasi bilangan bulat? Bu Evi menjawab kesulitan jika operasi bilangan bulat melibatkan beberapa tanda operasi misalkan penjumlah bilangan bulat positif dan bilangan bulat negatif. Biasanya diatasi dengan menggunakan garis bilangan. Setelah melaksanakan wawancara kemudian dilanjutkan dengan proses pembelajaran yang dibantu oleh Bu Evi. Proses pembelajaran dapat terlihat melalui gambar sebagai berikut:

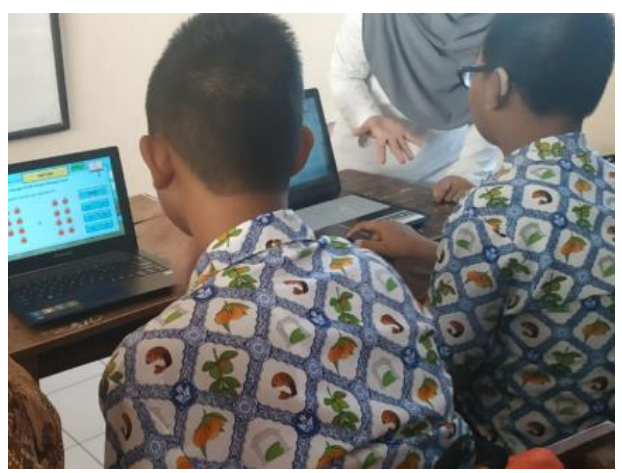

Gambar 7 Proses Pembelajaran

Proses pembelajaran semuanya menggunakan multimedia yang sudah digunakan. Media menggunakan satu orang memegang satu laptop. Terlihat mereka asyik dan termotivasi dalam pembelajaran. Bu Evi membantu untuk memotivasi dan membantu sesekali dalam mengarahkan jawaban siswa. Siswa semangat dan pada pertemuan pertama sudah bertanya kapan kesini lagi untuk belajar matematika.

Peneliti merasa termotivasi karena siswa sangat antusias dalam pembelajaran. Setelah pembelajaran dilaksanakan selama empat pertemuan dilakukan tes untuk mengetahui kemampuan siswa dalam memahami operasi bilangan bulat. Hasil tes yang dilakukan sebanyak dua kali didapatkan hasil untuk siswa pertama pada tes pertama mendapatkan 60 kemudian tes kedua mendapatkan nilai 70. Sementara siswa kedua pada tes pertama mendapatkan nilai 45 dan pada tes kedua mendapatkan nilai 70 . Hasil tersebut memberikan gambaran 
bahwa penggunaan multimedia mampu meningkatkan kemampuan siswa dalam mengoperasikan bilangan bulat. Setelah proses pembelajaran di laksanakan peneliti melakukan wawancara untuk melihat respon terhadap penggunaan multimedia tersebut. Respon sangat positif bahkan kedua siswa merasa senang belajar matematika menggunakan media yang dibuat.

Hasil dari penelitian memberikan gambaran bahwa jika multimedia dirancang dengan baik mampu meningkatkan kemampuan pemahaman siswa. Hal ini sesuai dengan penelitian yang dilakukan oleh Agus salim dengan judul Pembelajaran Matematika Berbasis Komputer Dengan Metode Multikomunikasi Untuk Siswa Kelas IV SDLB Penyandang Tuna Rungu Dan Wicara. Hasil penelitian menggambarkan bahwa menggunakan aplikasi ini, mengajar dan kegiatan belajar menjadi lebih menyenangkan dan dapat mempersingkat waktu mengajar .. Penelitian menunjukkan bahwa orang tuli lebih terfokus pada materi pembelajaran mereka dibandingkan dengan pembelajaran konvensional. Metode ini membuat orang belajar $40 \%$ lebih cepat daripada metode konvensional (Salim, 2015). Oleh karena itu perlu adanya inovasi dalam pembelajaran matematika khususnya pada siswa berkebutuhan khusus sehingga mampu memotivasi dalam belajar matematika.

\section{PENUTUP}

\section{Simpulan}

Simpulan dari hasil penelitian ini adalah multimedia yang dirancang dengan baik dipandang positif oleh siswa tuna rungu SLB N Majalengka. Hasil lain adalah kemampuan siswa dalam memahami operasi bilangan bulat meningkat setelah penggunaan multimedia.

\section{Saran}

Melalui penelitian ini dapat dibuat saran diantaranya masukan untuk guru matematika agar dapat melakukan inovasi dalam pembelajaran, salah satunya adalah penggunaan media yang interakktif sehingga mampu meningkatkan motivasi siswa.

\section{DAFTAR PUSTAKA}

Cook, W. (2011). In Pursuit of the Traveling Salesman: Mathematics at the Limits of. Princeton NJ: Princeton University Press.

(NCTM), N. C. (2001). Executive Summary-Principles and Standards for School Mathematics. Reston VA: NCTM.

Brown, P. e. (2011). THE INTEGERS A guide for teachers - Years 7-

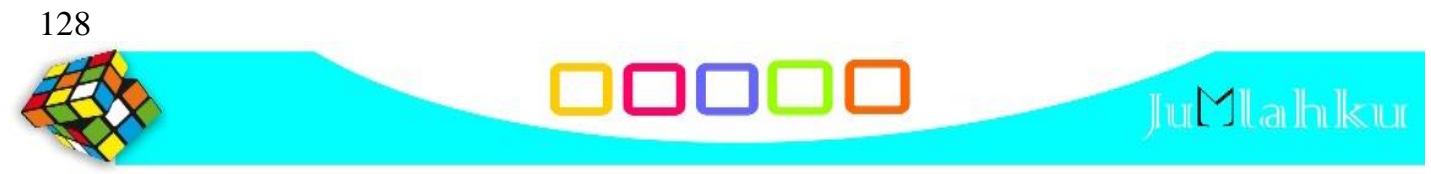


8. Australian: The Improving Mathematics Education in Schools (TIMES) .

Chee, T.S, \& Wong, A.F.L. (2003). Teaching and Learning with Technology. Singapore: Prentice Hall.

Csicsery, G. (2008). Hard Problems. the Road to the World's Toughest Math Contest,. Washington DC: Mathematical Association of America.

Devlin, K. J. (2012). Introduction to Mathematical Thinking. Palo Alto CA: published by Keith Devlin.

Fajrianto, R., \& Irawan, A. H. (2012). Perancangan Media Pembelajaran Interaktif Mata Pelajaran IPA Untuk Siswa Kelas VIII SMPLB Tunarungu Dengan Materi "Memahami Sistem Dalam Tubuh Manusia". JURNAL TEKNIK POMITS, 1-4.

Gunawan, I. (2013). Metode penelitian kualitatif. Jakarta: Bumi Aksara

Malatista, B.R., \& Sediyono, E. (2011). odel Pembelajaran Matematika untuk Siswa Kelas IV SDLB Penyandang Tunarungu dan Wicara dengan Metode Komtal Berbantuan Komputer. Jurnal Informatika, 7(1), 7-26.

Mulyadi, M. (2011). Penelitian kuantitatif dan kualitatif serta pemikiran dasar menggabungkannya. Jurnal studi komunikasi dan media, 15(1), 128-137.

Munir. (2013). MULTIMEDIA Konsep dan Aplikasi dalam Pendidikan. Bandung: Alfabeta.

Reddi, U.V. (2003). Multimedia as an educational tool. In Educational multimedia: $A$ handbook for teacherdevelopers. New Delhi: CEMCA.

Salim, A. (2015). Pembelajaran Matematika Berbasis Komputer Dengan Metode Multikomunikasi Untuk Siswa Kelas IV SDLB Penyandang Tuna Rungu Dan Wicara. Jurnal Techno Nusa Mandiri, XII, 77-95. 